\title{
Movimentos e protestos sociais: uma abordagem sob a ótica da teoria da mobilização política
}

\begin{abstract}
Maria da Glória Gohn'
Johnston, Hank. States \& Social Movements. Cambridge: Polity Press, 2011, 230 p.

Hank Johnston é professor da University of Califórnia, USA, campus San Diego, pesquisador de longa data da temática dos movimentos sociais e coeditor da revista Mobilization, juntamente com Marco Giuni e Rory MacVeigh. Seu novo livro States \& Social Movements, publicado em 2011 pela Polity Press, traz contribuições inovadoras e sugestivas para o estudo dos movimentos, protestos e mobilizações sociais, tanto do ponto de vista teórico-metodológico quanto da pesquisa empírica. Do ponto de vista teórico, Johnston adota o referencial desenvolvido nos anos de 1990, por C.Tilly e Sidney Tarrow, denominado como Teoria da Mobilização Política (TMP), que revigorou e renovou o debate sobre as ações coletivas na sociedade e suas relações no campo político. Em 1996, durante um programa de Pós-Doutoramento na New School University, tive a oportunidade de participar de dois seminários semestrais de Charles Tilly na Colombia University. Após a conclusão do programa, publiquei, em 1997, o livro Teorias dos Movimentos Sociais: paradigmas clássicos e contemporâneos, onde denominei a abordagem de Tilly e Tarrow como Teoria da Mobilização Política (TMP), dada à ênfase aos ciclos e processos de mobilizações sociopolíticas e
\end{abstract}

1 Professora titular da Faculdade de Educação da Universidade Estadual de Campinas (UNICAMP) e da Universidade Nove de Julho (UNINOVE), é vice-presidente do Comitê Social Movements and Social Classes da Associação Internacional de Sociologia (ISA). Publicou 16 livros de autoria individual e inúmeros em coletâneas. 
Movimentos e protestos sociais: uma abordagem sob a ótica da teoria da mobilização política

Maria da Glória Gohn

o foco nas organizações e nos processos de institucionalização das ações coletivas (GOHN, 2011). Alguns autores denominam a mesma abordagem como Teoria do Processo Político (TPP). A TMP foi construída a partir de debates que tiveram com outras teorias, a exemplo da Teoria da Escolha Racional dos anos de 1960 de M. Olson, reconstruída pela TMP; a Teoria da Mobilização de Recursos de John McCarthy e Mayer Zald e outros, dos anos de 1970, bastante criticada na TMP; críticas às velhas abordagens sobre o collective behavior, herança das abordagens psicossociais que predominaram na primeira metade do século XX (vide SMELSER, 1963). A TMP dialogou também com as teorias culturais e identitárias de autores europeus, tais como a dos Novos Movimentos Sociais (A. Touraine, A. Melucci), e com a produção norte-americana sobre os movimentos sociais nos debates sobre as questões: estruturas $\mathrm{x}$ ações dos atores (J. Cohen).

A TMP foi muito pouco utilizada no Brasil nas décadas de 1980/1990, quando surgiram vários estudos e publicações sobre a "era movimentalista" dos movimentos sociais no Brasil. Neste novo século a abordagem de Tilly e colaboradores tem sido "redescoberta" e utilizada por vários pesquisadores e professores de universidades brasileiras. Foi traduzido para o português um dos livros mais conhecidos do grupo: Power in Movement, de Sidney Tarrow (publicado nos USA em 1994, edição revista em 1998 a qual foi a base para a tradução para o português em 2009). A abordagem de Tarrow focaliza as relações entre as ações coletivas e o estado, buscando reconstruir seus "frames" - quadros e repertórios de atuação, localizando-as no tempo em termos de média ou longa duração, destacando os processos de oportunidades políticas construídos, assim como priorizando a dimensão cultural dos atores em cena.

Contentious Politics (disputas políticas) passaram a ser, no novo século, a marca diferencial da TMP. Categoria inicialmente desenvolvida por Tilly, reconfigurada em trabalho com Tarrow, recebeu contribuições posteriores de Doug McAdam. No novo século ela foi adotada por outros autores da mesma corrente como 
Mário Diani, David Meyer, H. Johnston, Jeff Goodwin etc. Ela envolve diferentes formas e combinações da ação coletiva (vide TILLY, TARROW, 2007).

$\mathrm{O}$ interesse do livro de Johnston apresentado nesta resenha para o estudo das diferentes formas de ações coletivas e de movimentos sociais é dado, pelo enfoque teórico metodológico como pelo leque das temáticas tratadas. Ele focaliza as ações expressas em movimentos e protestos civis não apenas em regimes democráticos, mas também em regimes repressivos, apresentando inúmeros exemplos de mobilizações, tanto no Ocidente como no leste europeu e alguns casos do Oriente Médio (Cap. 4). Registre-se que o livro foi escrito antes do ciclo de mobilizações e movimentos iniciados em 2011 com a Primavera Árabe no Oriente Médio, ou os Indignados da Espanha e outros países. Occupy Wall Street dos USA e outros países não também não tinha nascido. Johnston usa o método comparativo e seu estilo é agradável para a leitura, ele usa como didática tratar os temas em pequenos trechos com subtítulos, despertando a atenção do leitor. O livro atende um público que vai além da academia, tais como as ONGs, entidades públicas governamentais e a mídia mais informada, que acompanha as marchas e movimentações pelo mundo.

O livro divide-se em seis capítulos, a saber: 1) O estado, protesto e os movimentos sociais; 2) Protestos na sociedade contemporânea; 3) Sociedade de movimentos sociais; 4) Protestos em estados repressivos; 5) Revoluções e estados; 6) Globalização, protestos e estado.

A tese fundamental do autor é desenvolvida nos capítulos 1 e 2 e diz: no século XXI o estado é alvo da grande maioria das campanhas de protestos e movimentos sociais. Por isso, estes protestos e movimentos são considerados como parte da política; eles são políticos porque as pessoas que participam dele estão exercitando a política, e não porque seja parte das elites políticas que lutam pelo poder. Estão participando das disputas políticas pela direção ou significado das demandas, reivindicações ou protestos em tela. 
Movimentos e protestos sociais: uma abordagem sob a ótica da teoria da mobilização política

Maria da Glória Gohn

O capítulo 3 do livro apresenta esta tese mais desenvolvida - a de que os movimentos sociais não são fenômenos extraordinários ou apenas agentes de contestação porque eles têm um papel na sociedade moderna - papel de expressar as reivindicações dos cidadãos; mobilizações e protestos tornaram-se formas rotineiras de participação política. Passou a ocorrer uma institucionalização dos protestos. Certamente que esta tese - central para a abordagem da TMP, não é unânime em outras abordagens sobre os movimentos sociais. Os críticos argumentam que o olhar sob o prisma da institucionalização despolitiza os protestos enquanto formas ideológicas, formas que contém projetos e culturas políticas específicas; e ressignifica-os como elementos componentes do próprio jogo democrático. Entretanto, talvez este seja o ponto mais interessante da obra porque esta ressignificação tem sido a base de interpretação não só de analistas/estudiosos da TMP sobre os movimentos, mas este enfoque tem tido adeptos também entre aqueles que fundamentam as políticas públicas participativas. $\mathrm{O}$ livro contribui para entender as políticas públicas de muitos países latino-americanos na atualidade, especialmente no Brasil; ele possibilita-nos fazer a "leitura da leitura" dos formuladores das políticas públicas.

No capítulo 5 o livro trata de mobilizações em estados que vivenciaram processos revolucionários, destacando a América Central e alguns países da América do Sul. O capítulo 6 focaliza os protestos antiglobalização e seus diferentes formatos de redes. Esta parte é atualíssima.

O autor recorre à História para demonstrar, via exemplos, que as relações entre protesto e estado datam de dois séculos passados. Entretanto, há grandes diferenças neste longo período. Antes de examinar estas diferenças ele indaga: $O$ que é exatamente o Estado? A partir de Hobbes, Rousseau e Locke o autor busca as justificativas para a existência do Estado (prover alimentos, água, bem comum, proteção aliados, direitos, impostos, extração de recursos naturais etc.). Concluiu que as necessidades da guerra e segurança das fronteiras territoriais foram forças-chave para for- 
matar o estado moderno. Retoma M Weber quando este aborda o monopólio da força de um dado território. Johnston não compartilha da tese marxista que vê o estado como comitê executivo da burguesia e nem com as análises de Poulantzas. Para ele o estado é uma arena onde conflitam interesses das elites políticas, econômicas e do estado (burocracias e servidores civis) e pressões populares. Os protestos têm um significado não institucional de fazer reivindicações ou demandas quando as autoridades estatais, por limitar, ignorar ou fechar canais institucionais de acesso, não respondem às pressões populares.

Utilizando-se de metodologias da TMP Johnston recupera os repertórios de protestos dos movimentos em diferentes tempos históricos. Enquanto o repertório moderno se expressa por meio de encontros, marchas, demonstrações, e greves, nos períodos anteriores, em sociedades predominantemente agrárias, tradicionais, e altamente estratificada, os protestos eram focalizados, de duração limitada, com ações diretas contra os oponentes, responsáveis por atos de injustiças.

O texto recupera os estudos de Charles Tilly, E. Hobsbawm, G. Rude e outros sobre os protestos populares na Inglaterra entre 1758 a 1834, para caracterizar a sociedade da época e os repertórios dos protestos. Segundo o autor, o repertório moderno dos movimentos sociais emerge no início do século XIX, de forma cosmopolita (problemas abrangentes, nacionais), autônoma e modular (incluindo táticas como: marchas, demonstrações, encontros, petições, debates etc.). Estas formas colocaram as questões da participação e da cidadania em pauta (especialmente o voto), assim como deram lugar às organizações de trabalhadores, sociedades e clubes. Johnston tem grande preocupação em diferenciar movimentos sociais de ações de protestos de grupos. Por exemplo, as lutas das sociedades abolicionistas do passado não são vistas como movimentos sociais, mas como organizações de movimentos sociais. O autor conclui que as mobilizações dos movimentos sociais atuais tornaram-se uma forma de acompanhamento das políticas e representam uma mudança em 
Movimentos e protestos sociais: uma abordagem sob a ótica da teoria da mobilização política

Maria da Glória Gohn

relação ao passado quando as ações coletivas nasciam em face da exclusão e não responsabilização do estado.

Em síntese, o livro de Johnston traz importantes contribuições para a análise do passado; para o entendimento do presente; e para o diagnóstico de prováveis caminhos futuros a serem trilhados pelas ações coletivas nas sociedades civis da atualidade.

\section{Referências}

COHEN, Jean. "Strategy or Identity: New Theoretical Paradigms and Contemporary Social Movements". Social Research, n. 52, p. 663-716, 1985.

DIANI, Mário; McADAM Doug. (Eds.). Social movements and networks: Relational approaches to collective actions. Oxford, Oxford University Press, 2003

GOHN, Maria da Glória. Novas teorias dos movimentos sociais. 3. ed. São Paulo: Loyola, 2010.

- Teorias dos movimentos sociais: paradigmas clássicos e contemporâneos. 9. ed. São Paulo: Loyola, 2011.

GOODWIN, Jeff; JASPER, James M. The Social Movements ReaderCases and Concepts. Oxford, Blackwell, 2003.

JOHNSTON, Hank. "New Social Movements and Old Regional Nationalisms". In: LARAÑA; JOHNSTON; GUSFIELD. New Social Movements: From Ideology to Identity. Philadelphia, Temple Un. Press, 1994.

. 1995. "A Methodology for Frame Analysis: From Discourse to Cognitive Schemata. In: JOHNSTON, H.; KLANDERMANS, B. Social Movements and Culture. Mineapolis, USA, University of Minnesota Press. p. 217-246. 
.; ALMEIDA, Paul. Latin American social movements:

globalization, democratization and transnational networks. $\mathrm{N}$. York: Rowman \& Littlefield Publishers, 2007.

McADAM, Doug; McCARTHY, John D.; ZALD, Mayer N. Comparative perspectives on social movements. Cambridge: Cambridge Un. Press, 1996.

McCARTHY, John D.; ZALD, Mayer. The Trends of Social Movement in America: Professionalization and Resource Mobilization. Morristown, N.J, General Learning Press, 1973.

.;_ . . "Resource mobilization and social movements". American Journal of Sociology, n. 82, p. 1212-1241, 1977. ; .The dynamics of social movements: resource mobilization, social control, and tatics. Cambridge, Mass: Wintrop, 1979.

MELUCCI, Alberto. The New social movements: a theoretical approach. Social Science Information, n.19, p. 199-226, 1980.

. Nomads of the present: social movements and individual needs in contemporary society. Philadelphia: Temple University Press, 1989

. Challeging codes. Cambridge: Cambridge Press, 1996.

MEYER, David S.; MINKOFF, Debra C. Conceptualizing political opportunity. Social Forces, v. 82, n. 4, p. 1457-1492, June 2004.

MORRIS, Aldon D.; MUELLER, Carol M. Frontiers in social movement theory. New Haven: Yale University Press, 1992

OLSON, Mancur.The Logic of Collective Action. Cambridge, University Press, 1965.

RUDÉ, George. Ideologia e protesto popular. Rio de Janeiro: Zahar, 1982. 
Movimentos e protestos sociais: uma abordagem sob a ótica da teoria da mobilização política

Maria da Glória Gohn

- La multitud en la historia. Estudio de los disturbios populares en Francia e Inglaterra, 1730-1848. Buenos Aires: Siglo XXI, 1971.

SMELSER, Neil J. Teoria del comportamiento colectivo. México, FCE, 1962.

SNOW, David; SOULE, Sarah A; KRIESI, Hanspeter. The Blackwell Companion to social movements. London: Blackewell, 2004.

TARROW, Sidney. Power in movement. Cambridge: Cambridge Press, 1994.

Press, 2005.

. New Transnational Activism. Cambridge: Cambridge

TILLY, Charles. From Mobilization to Revolution. Londres: AddisonWesley, 1978.

. Identities, boundaries \& social ties. London: Paradigm Publishers, 2005.

.; TARROW, Sidney. Contentious politics. London: Paradigm Publishers, Boulder, 2007

TOURAINE, Alain. Sociologie de l'action. Paris: Seuil, 1965.

. A sociedade post-industrial. Lisboa: Moraes, 1970.

. Le communisme utopique. Paris: Seuil, 1972.

. Production de la société. Paris : Seuil, 1973.

. Palavra e sangue. Campinas: Unicamp, 1989.

. Crítica da Modernidade. Petrópolis: Vozes, 1994.

TURNER, Ralph H.; KILLIAN, Lewis M. Collective Behavior. New York: Prentice-Hall, 1957. 